\title{
Rickets in a Crab-eating Fox (Cerdocyon thous)
}

\author{
Alana Macena Anselmo', Andre Saldanha', Eloisa Muelbahuer', Danielle Buch', Mariana Reffatti De Oliveira', \\ Ana Sílvia Miranda Passerino ${ }^{2}$, Rogerio Ribas Lange' ${ }^{1}$ Tilde Rodrigues Froes ${ }^{1}$
}

\begin{abstract}
Background: Calcium is essential for the healthy development of animals, especially regarding bone formation. Diverse factors influence calcium metabolism, and failure in any of these points may result in metabolic bone diseases. Rickets is an uncommon disease of growing bones occurring exclusively in young animals, it is characterized by the failure of osteoid to calcify and can be a result of lack of vitamin D, imbalance of calcium and phosphorus or hereditary conditions. Nutritional origin is more frequent in veterinary medicine, but it has become rarer after the availability of balanced commercial rations. This report describes the diagnosis and treatment of rickets in a crab-eating fox puppy.

Case: A 3-month-old male crab-eating fox was presented with ataxia and angular deviation of the tibia and radius/ulna with suspected osteometabolic disease. It was part of a group of three orphan siblings hand-raised. The other two siblings did not present any clinical signs. All three animals presented pale mucous membranes and were infected by ancylostoma, coccidia, toxocara, and sarcocystis. Radiographic findings of the affected animal showed generalized osteopenia of the entire skeleton associated with widening radiolucent distal physeal plates and cupping of the metaphysis, changes classical of rickets. The other two siblings presented no skeletal alterations and complete blood count and biochemistry of all three animals were taken for comparison, including serum vitamin D and PTH. All three animals presented lymphopenia (5.4-9.3 x 103/uL, reference range 10.3-16.5 x 103/uL), hypoproteinemia (5.1-5.3 g/dL, reference range 5.9-8.2 g/dL), low levels of creatinine $(0.4-0.6 \mathrm{mg} / \mathrm{dL}$, reference range $0.7-1.2 \mathrm{mg} / \mathrm{dL})$, increased ALP (181-285 U/L, reference range 209.7-267 U/L) and CK (421-500 U/L, reference range for domestic dogs 16-140 U/L). The affected fox presented ionized calcium $(10.9 \mathrm{mg} / \mathrm{dL}$, reference range for domestic dogs 9.3-11.5 mg/dL) and vitamin $\mathrm{D}(26.4 \mathrm{ng} / \mathrm{mL}$, reference range for domestic dogs $9.5-129 \mathrm{ng} / \mathrm{mL})$ close to the inferior limits associated with elevated phosphorus $(8.8 \mathrm{mg} / \mathrm{dL}$, reference range for domestic dogs $2.5-5.6 \mathrm{mg} / \mathrm{dL})$ and PTH $(4.3 \mathrm{pg} / \mathrm{mL}$, reference range for domestic dogs $<2.82 \mathrm{pg} / \mathrm{dL})$. Besides that, the affected animal presented the quickest development (weight gain) among the offspring.

Discussion: Recent reports of rickets in veterinary medicine are not common. The advent of balanced commercial rations and improvement in animal husbandry reduced the frequency of this condition. Wild species are more frequently reported to present metabolic bone disease due to inadequate nutritional management of the different species. Bone formation and growth are result of the deposition of hydroxyapatite crystals and it depends on calcium intake or absorption, adequate serum vitamin D levels and proper calcium and phosphorus balance. All these three situations were breached in this case report, resulting in a multifactorial scenario for development of rickets in this crab-eating-fox. Radiographic exam, complete blood count, biochemistry, and clinical response to dietary correction confirmed the diagnosis of rickets with nutritional origin. Hereditary rickets had been described in people and a domestic dog, but not in wildlife species. The animal responded well to clinical and nutritional management, presenting clinical response within a couple of weeks. This is the first report of rickets in this species as well as dosage of serum vitamin D and PTH in crab-eating foxes.
\end{abstract}

Keywords: nutrition, osteometabolic disease, carnivora, radiograph, endocrinology.

DOI: $10.22456 / 1679-9216.101191$

Accepted: 24 July 2020

Published: 20 August 2020

${ }^{1}$ Department of Veterinary Medicine, Federal University of Paraná (UFPR), Curitiba, PR, Brazil. ${ }^{2}$ Municipal City Hall of Curitiba (PMC), Curitiba. CORRESPONDENCE: A. Saldanha [saldanha255@gmail.com]. DMV - UFPR. Rua dos Funcionários n. 1540. CEP 80035-050 Curitiba, PR, Brazil. 


\section{INTRODUCTION}

Rickets is an uncommon condition that affects the skeletal system of growing animals. It is characterized by reduction in the epiphyseal mineralization of bones (incomplete calcification) and in the cartilaginous portion of the growth plate. Typically, the condition is nutritional in origin, related to an unbalanced and/or inadequate absorption of nutrients that causes dietary insufficiencies of calcium, phosphorus or vitamin D [3]. The main clinical manifestations associated with rickets are apathy, muscle weakness and bowing of the bones. On the physical exam, nodular growths in the bone extremities, also known as a rachitic rosary, can eventually be noted [3]. Rickets has been reported in puppies of different breeds $[1,8,12]$, and also in double-crested cormorants [16], lions [2], polar-bears [10] and non-human primates $[9,15]$. Osteomalacia refers to the same condition, but in adults, when the physeal plates are closed, and the condition behaves slightly differently. Osteomalacia is reported in wild species such as skunks [5] and marmosets [6].

\section{CASE}

An intact male crab-eating fox (Cerdocyon thous), approximately 3-month-old, presented with ataxia and angular deviation of the tibia and radius/ulna (animal 2). The animal was from a litter of 5 animals, hand reared after domestic dogs had attacked their mother. The puppies were only given milk for a couple of weeks, and only 3 survived (animals 1, 2 and 3 ). The animals were handed to the environmental police who fed them powdered milk, fruits, and infant formula 4 times a day for a month, at which point the animals were handed to the zoo due to their overall poor condition. Following a physical examination in the zoo, all 3 puppies were found to have pale mucous membranes, physiological parameters within normal limits and no skeletal abnormalities were noted on palpation. Severe infestation by Ancylostoma, Coccidia, Toxocara, and Sarcocystis was diagnosed on fecal exam. Deworming was performed with sulfadiazine and trimethoprim $\left(\text { Diazil }^{\circledR}\right)^{1} 30 \mathrm{mg} / \mathrm{kg}$ and a commercial deworming compound containing pyrantel pamoate, praziquantel and febantel $\left(\text { Vermivet }^{\circledR}\right)^{2}$. Diet was modified to include fruits, vegetables, meat, eggs, petit-suisse cheese, dog ration and powdered vitamin complex. Twenty days later, the fecal exam was clean, and metabolic disease was suspected in one of the puppies due to ataxia and angular deviation of the tibia and radius/ ulna, and the diet was supplemented with mice. The history is summarized in Figure 1. Due to suspicion of osteometabolic disease, radiographs of the patient and siblings (for comparison) were performed. Blood samples were collected for complete blood count and biochemistry. Radiographs of axial and appendicular skeleton in orthogonal projections in all three siblings were performed. In the affected dog there was generalized osteopenia with thinning of the cortices, widened and radiolucent distal physeal plates, and the classical cupping appearance of the metaphysis of the distal diaphysis of radius in both sides. Additionally, asymmetry in the growth of the radius and ulna could be seen. Joints and adjacent soft tissues were preserved and within radiographic normal range. No abnormalities were observed in the radiographs of the other animals (Figure 2). Complete blood count and blood chemistry results are summarized in Table 1.

\section{DISCUSSION}

Bone formation and growth depend on the deposition of hydroxyapatite crystals that are formed by calcium and phosphorus, while vitamin $\mathrm{D}$ is crucial for calcium absorption in the enterocytes [20]. The development of rickets, although mostly caused by nutritional disorders, can be related to abnormalities at any stage of calcium metabolism, from intake, absorption to metabolism. Nutritional disorders are the most common cause of rickets in puppies, generally due to low availability or imbalance of calcium and phosphorus

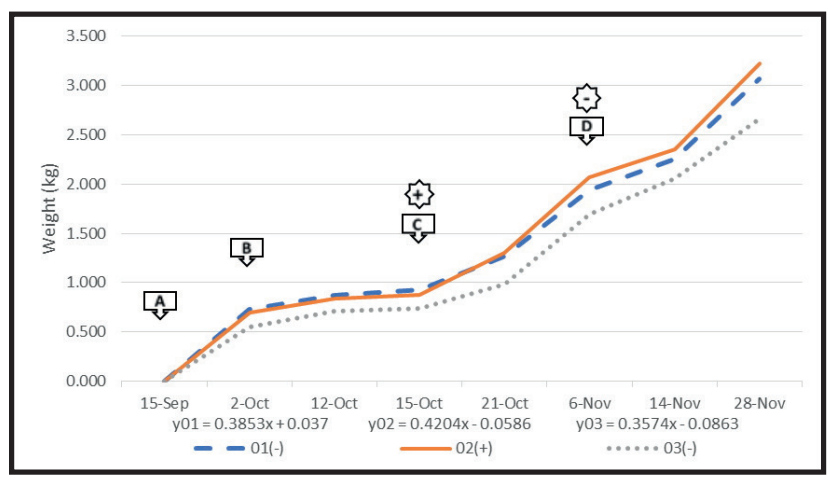

Figure 1. Growth curves of the crab-eating foxes. Dash line - Animal 01, healthy animal. Solid line - Animal 02, affected animal. Dotted line - Animal 03 , healthy animal. Linear trendlines are represented by " $y=a x+b "$, where "a" represents the slope of the line, and therefore, a higher "a" value suggests a more intense growth spur in animal 02-0.42 against 0.38 and 0.35. Diets: A- Milk. B- Powdered milk, fruits, and infant formula. C- Fruits, vegetables, meat, eggs, petit-suisse cheese, dog ration and powdered vitamin complex. D- Fruits, vegetables, meat, eggs, petit-suisse cheese, dog ration and powdered vitamin complex and mice. Fecal exam: (+) - Positive. (-) - Negative. 


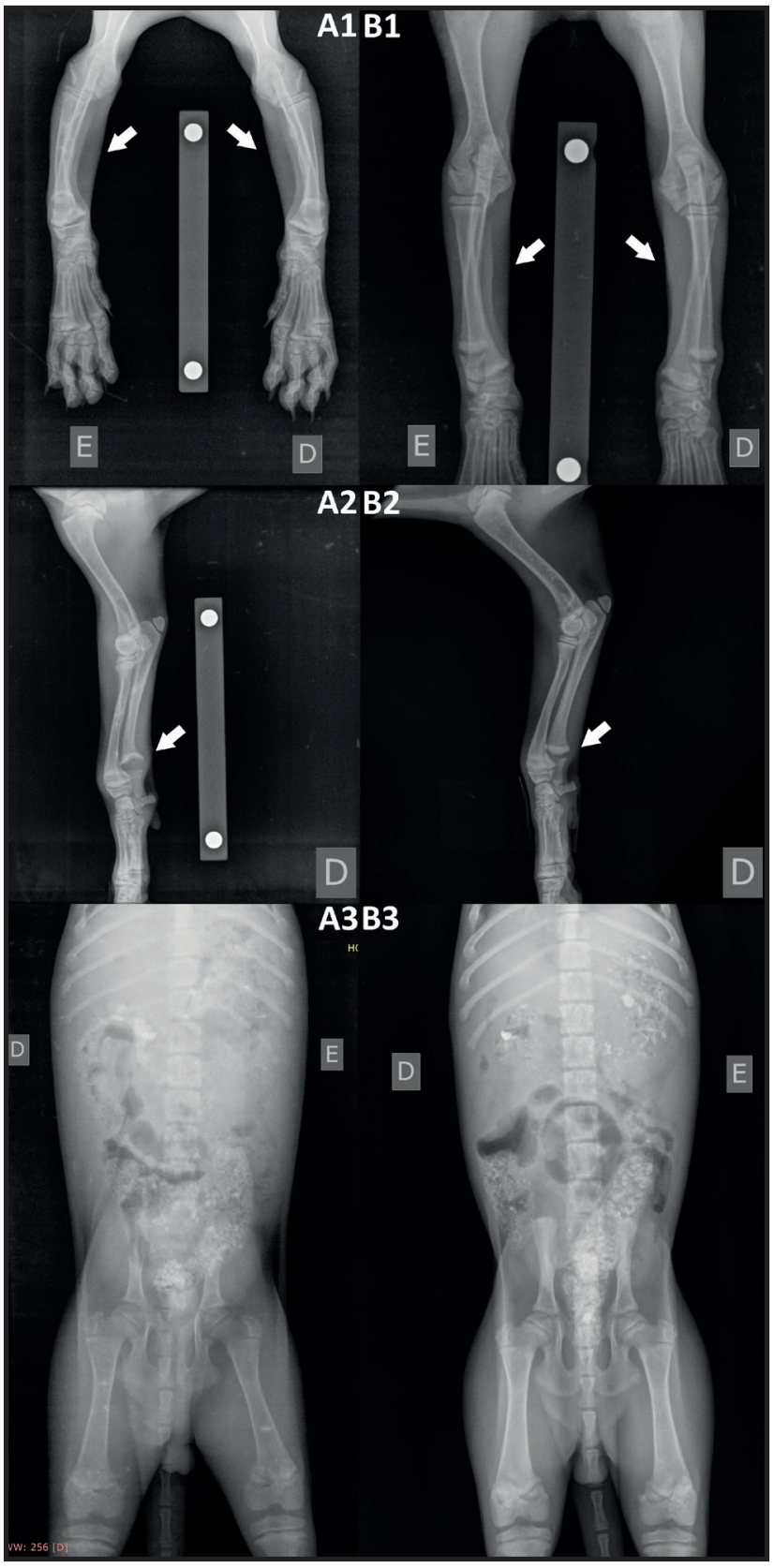

Figure 2. Radiographic findings of the crab-eating foxes. Figures A- Animal 02 . Figures B- Animal 03. Bilateral bowing of the radius is evident in affected animal (A1) and absent in non-affected (A2). Widening radiolucent distal physeal plates with classical cupping appearance of the metaphysis in the right forelimb of the affected fox (B1) and normal appearance in non-affected (B2). Generalized osteopenia of the skeleton, with thinning of the cortices in affected animal (A3) and normal appearance in the healthy animal.

[3]. Hypovitaminosis D, due to dietary deficiency, is also a frequent cause [12]. Vitamin D3 (cholecalciferol) is present in food of animal origin, calcitriol being the main active metabolite in the organism [20]. Previtamin D3 can also be converted into vitamin D3 through the action of ultraviolet $\mathrm{B}$ in the skin in some species, but not in dogs [7]. Vitamin D metabolites are essential in calcium metabolism; regulating its active absorption from intestines, renal regulation, deposition and mobilization from bones [20].

Considering that all 3 crab-eating foxes were fed the same diet, a genetic condition affecting vitamin D receptors was suspected in the affected animal. There is a previous report of a juvenile dog eating a commercial puppy food that developed rickets and failed to improve after high doses of vitamin D supplementation [11]. The animal had a rare gene mutation resulting in a hereditary Vitamin D-resistant rickets, and was therefore refractory to improvements in nutrition. The biochemistry panel is a useful tool for diagnosis of rickets. The crab-eating foxes had calcium, ionized calcium and vitamin D within the reference values while phosphorus was elevated. The values of serum PTH were higher in the affected dog than in the unaffected siblings. In domestic dogs, vitamin D levels may also be within normal limits [3], and little difference was noted between affected and non-affected puppies. Serum vitamin D, calcium and phosphorus may be in the normal range because of physiological mineral mobilization from the skeleton - secondary hyperparathyroidism. Dogs are unable to synthesize vitamin D3 through the skin, even under UVB exposure, making them dependent on vitamin D3 in the diet [7], therefore dietary supply rapidly affects serum levels of the vitamin [18]. Rapid clinical improvement and normalization of vitamin $\mathrm{D}$ concentration is reported after balancing the diet, while only the PTH concentration remained slightly elevated up to four months later [4], similar to findings in this affected puppy. PTH was analyzed by chemiluminescence, a technique less sensitive than immunoradiometric assays [14], explaining levels below limit of detection in the unaffected puppies and the elevated levels in the rachitic animal. Also, blood samples were collected after the dietary change, when clinical improvement was noticeable and this may explain why values of calcium and vitamin D were within reference values, phosphorus slightly elevated and PTH still increased in the affected dog compared to the others.

Considering the clinical condition, radiographic findings and blood exams, this crab-eating fox was diagnosed with rickets. Nutritional origin was confirmed by the good response to husbandry and diet correction. A polar bear cub was reported to develop rickets more severely than others due to a faster growth 
Table 1. Results of CBC and biochemistry of the affected crab-eating fox by comparing reference values for crab-eating foxes and domestic dogs.

\begin{tabular}{|c|c|c|c|c|c|c|}
\hline Blood test & Unit & 01(-) & $02(+)$ & 03(-) & Crab-eating fox & Domestic dog \\
\hline WBC & $10^{3 / u L}$ & 5.4 & 9.3 & 7.2 & $10.3-16.5^{*}$ & $6000-17000^{\dagger}$ \\
\hline Lymphocytes & $10^{3} / \mathrm{uL}$ & 1.50 & 1.90 & 2.50 & $1.47-2.47 *$ & $0.59-3.3^{\dagger}$ \\
\hline Monocytes & $10^{3} / \mathrm{uL}$ & 0.40 & 0.70 & 0.60 & $0.21-0.66^{*}$ & $0.075-1.0^{\dagger}$ \\
\hline $\mathrm{RBC}$ & 106/uL & 3.69 & 4.00 & 4.14 & $3.73-4.56^{*}$ & $5.5-8.5^{\dagger}$ \\
\hline Hemoglobin & $\mathrm{g} / \mathrm{dL}$ & 10.8 & 11.3 & 12.3 & $10.3-12.6^{*}$ & $12-18^{\dagger}$ \\
\hline $\mathrm{PCV}$ & $\%$ & 34.0 & 35.5 & 38.0 & $34-40 *$ & $5.7-8.01^{\dagger}$ \\
\hline $\mathrm{MCV}$ & $\mathrm{fL}$ & 92.30 & 88.80 & 92.00 & $87.47-93.67 *$ & $60-72^{\dagger}$ \\
\hline $\mathrm{MCHC}$ & $\mathrm{g} / \mathrm{dL}$ & 31.70 & 31.80 & 32.30 & $30.29-31.50 *$ & $33-38^{\dagger}$ \\
\hline Platelets & $103 / \mathrm{uL}$ & 302 & 302 & 385 & $249-291^{*}$ & $190-468^{\dagger}$ \\
\hline Sodium & $\mathrm{mEq} / \mathrm{L}$ & 144.6 & 143.4 & 143.7 & NA & $140-156^{\dagger}$ \\
\hline Potassium & $\mathrm{mg} / \mathrm{dL}$ & 5.05 & 5.39 & 5.38 & NA & $4.1-5.5^{\dagger}$ \\
\hline Calcium & $\mathrm{mg} / \mathrm{dL}$ & 11.40 & 10.90 & 11.00 & NA & $9.3-11.5^{\dagger}$ \\
\hline Ionized Calcium & $\mathrm{mmol} / \mathrm{L}$ & 1.447 & 1.422 & 1.421 & NA & $1.30-1.46^{\dagger}$ \\
\hline Chloride & $\mathrm{mEq} / \mathrm{L}$ & 114.70 & 113.60 & 115.10 & NA & $108-122^{\dagger}$ \\
\hline Total protein & $\mathrm{g} / \mathrm{dL}$ & 5.1 & 5.3 & 5.2 & $5.9-8.2^{*}$ & $5.2-7.4^{\dagger}$ \\
\hline Albumin & $\mathrm{g} / \mathrm{dL}$ & 2.5 & 2.6 & 2.6 & $2-2.9^{*}$ & $3.0-3.9^{\dagger}$ \\
\hline Phosphorus & $\mathrm{mg} / \mathrm{dL}$ & 9.3 & 8.8 & 9.4 & NA & $2.5-5.6^{\dagger}$ \\
\hline Creatinine & $\mathrm{mg} / \mathrm{dL}$ & 0.5 & 0.6 & 0.4 & $0.7-1.2 *$ & $0.7-1.5^{\dagger}$ \\
\hline Urea & $\mathrm{mg} / \mathrm{dL}$ & 25 & 31 & 29 & $27-39^{*}$ & $7.0-28^{\dagger}$ \\
\hline AST & $\mathrm{U} / \mathrm{L}$ & 26 & 32 & 26 & $12.19-37.81^{* *}$ & $42-175^{\dagger}$ \\
\hline ALT & $\mathrm{U} / \mathrm{L}$ & 37 & 40 & 28 & $11.5-22.5^{*}$ & $10-120^{\dagger}$ \\
\hline ALP & $\mathrm{U} / \mathrm{L}$ & 285 & 274 & 181 & $209.7-267 *$ & $16-140^{\dagger}$ \\
\hline CK & $\mathrm{U} / \mathrm{L}$ & 421 & 500 & 440 & NA & $43-234^{\dagger}$ \\
\hline Magnesium & $\mathrm{mg} / \mathrm{DL}$ & 1.9 & 1.8 & 1.7 & NA & $1.8-2.5^{\dagger}$ \\
\hline Vitamin D & $\mathrm{ng} / \mathrm{mL}$ & 26.4 & 26.4 & 25.3 & NA & $9.5-129^{\Delta}$ \\
\hline PTH & $\mathrm{pg} / \mathrm{mL}$ & $<1.2$ & 4.3 & $<1.2$ & NA & $<2.82^{\Phi}$ \\
\hline
\end{tabular}

Reference values = NA: Not available; *Mattoso et al. - for subadults crab-eating foxes [13]; **Novais [17]; †Thrall et al. $[19] ;{ }^{\Delta}$ Sharp et al. - for domestic dogs fed homemade diets [18]; \$Mooney et al. [14].

spurt [10]. The affected puppy in this report also showed a steeper growth curve compared to his siblings $1.23 \mathrm{~kg}$ against 0.99 and $1.07 \mathrm{~kg}$ in a one-month period (Table 1). Rickets can be treated by supplementation of vitamin $\mathrm{D}$, calcium and phosphorus, which should result in clinical improvement in approximately one month [1]. Not only was the hand-rearing diet of the siblings unbalanced but the severe concomitant parasitism probably compromised both the supply of calcium and vitamin D, and also their absorption. Despite a couple of dietary changes in these foxes some nutrient deficiency or imbalance can be noted at each point. The initial milk diet was deficient in vitamin D. Indoor-raised chimpanzees consuming only breast milk 
has been reported to develop rickets, following vitamin D supplementation the animals showed radiographic improvement within three weeks [9]. The next diet in the foxes had no components of animal origin. When animal products were finally provided, it was given as pieces of meat and not as complete prey, resulting in an imbalance of calcium and phosphorus. Clinical improvement was not seen until several weeks of provision of a complete balanced diet containing whole prey items and after parasitism had been treated.

In conclusion, since the introduction of commercial animal rations rickets is rarely described in domestic species [3]. The development of rickets in this crab-eating fox was the result of a multifactorial situation: successive unbalanced diets associated with a high degree of parasitism and a fast growth rate. The radiographic findings were crucial in the diagnosis, along with the biochemistry panel and clinical response of the patient to diet correction.

\section{MANUFACTURERS}

${ }^{1}$ Calbos Saúde Animal. São José dos Pinhais, PR, Brazil.

${ }^{2}$ BioVet Vaxxinova. Vargem Grande Paulista, SP, Brazil.

Acknowledgments. The authors would like to thank Olair Carlos Beltrane for the availability in realizing the blood exams and technical information.

Declaration of interest. The authors report no conflicts of interest. The authors alone are responsible for the contents and writing of the paper.

\section{REFERENCES}

1 Arora N., Kumar T., Prasad A., Tufani N.A. \& Rajora V.S. 2012. Rickets in Growing Pups- Case Reports. Veterinary Practitioner. 13(1): 103-104.

2 Chesney R.W. \& Hedberg G. 2010. Metabolic bone disease in lion cubs at the London Zoo in 1889: the original animal model of rickets. Journal of Biomedical Science. 17(1): S36

3 Dittmer K.E. \& Thompson K.G. 2011. Vitamin D Metabolism and Rickets in Domestic Animals: A Review. Veterinary Pathology. 48(2): 389-407.

4 Fornel-Thibaud P., Blanchard G., Escoffier-Chateau L., Segond S., Guetta F., Begon D., Delisle F. \& Rosenberg D. 2007. Unusual Case of Osteopenia Associated with Nutritional Calcium and Vitamin D Deficiency in an Adult Dog. Journal of the American Animal Hospital Association. 43(1): 32-60.

5 Hanley C.S., Wilson G.H. \& Hernandez-Divers S.J. 2004. Secondary nutritional hyperparathyroidism associated with vitamin D deficiency in two domestic skunks (Mephitis mephitis). Veterinary Records. 155(8): 233-237.

6 Hatt J.M. \& Sainsbury A.W. 1998. Unusual case of metabolic bone disease in a common marmoset (Callithrix jacchus). The Veterinary Record. 143(3): 78-80.

7 How K.L., Hazewinkel H.A.W. \& Mol J.A. 1994. Dietary Vitamin D Dependence of Cat and Dog Due to Inadequate Cutaneous Synthesis of Vitamin D. General and Comparative Endocrinology. 96(1): 12-18.

8 Johnson K.A., Church D.B., Barton R.J. \& Wood A.K.W. 1988. Vitamin D-dependent rickets in a Saint Bernard dog. Journal of small Animal Practice. 29(10): 657-666.

9 Junge R.E., Gannon F.H., Porton I., McAlister W.H. \& Whyte M.P. 2000. Management and Prevention of Vitamin D Deficiency Rickets in Captive-Born Juvenile Chimpanzees (Pan troglodytes). Journal of Zoo and Wildlife Medicine. 31(3): 361-369.

10 Kenny D.E., Irlbeck A.N. \& Eller J.L. 1999. Rickets in Two Hand-Reared Polar Bear (Ursus maritimus) Cubs. Journal of Zoo and Wildlife Medicine. 30(1): 132-140.

11 Levine D.N., Zhou Y., Ghiloni R.J., Fields E.L., Birkenheuer A.J., Gookin J.L., Roberston I.D., Malloy P.J. \& Feldman D. 2009. Hereditary 1,25-Dihydroxyvitamin D-Resistant Rickets in a Pomeranian Dog Caused by a Novel Mutation in the Vitamin D Receptor Gene. Journal of Veterinary Internal Medicine. 23(6): 1278-1283.

12 Malik R., Laing C., Davis P.E., Allan G.S. \& Wigney D.I. 1997. Rickets in a litter of racing greyhounds. Journal of Small Animal Practice. 38(3): 109-114.

13 Mattoso C.R.S., Catenacci L.S., Beier S.L., Lopes R.S. \& Takahira R.K. 2012. Hematologic, serum biochemistry and urinary values for captive Crab-eating Fox (Cerdocyon thous) in São Paulo state, Brazil. Pesquisa Veterinária Brasileira. 32(6): 559-566.

14 Mooney C.T., Shiel R.E., Fawcett K., Matthews E. \& Gunn E. 2019. A comparison of canine whole and intact parathyroid hormone concentrations as measured by different assays. Journal of Small Animal Practice. 60(8): 507513. 
15 Morrisey J.K., Reichard T., Lloyd M. \& Bernard J. 1995. Vitamin-D-Deficiency Rickets in Three Colobus Monkeys (Colobus Guereza Kikuyuensis) at The Toledo Zoo. Journal of Zoo and Wildlife Medicine. 26(4): 564-568.

16 Nichols D., Montali R.J., Pickett C. \& Bush C. 1983. Rickets in Double-Crested Cormorants (Phalacrocorax auritus). The Journal of Zoo Animal Medicine. 14(3): 115-124.

17 Novais AA. 2003. Prevalência dos antígenos eritrocitários caninos em cães domésticos (Canis familiaris) e investigação dos parâmetros hematológicos e da ocorrência de antígenos eritrocitários em lobos-guará (Chrysocyon brachyurus) e cachorros-do-mato (Cerdocyon thous) criados no Brasil. 63f. Jaboticabal, SP. Tese (Doutorado) - Programa de PósGraduação em Medicina Veterinária, Faculdade de Ciências Agrárias e Veterinárias de Jaboticabal.

18 Sharp C.R., Selting K.A. \& Ringold R. 2015. The effect of diet on serum 25-hydroxyvitamin D concentrations in dogs. BMC Research Notes. 8: 442.

19 Thrall M.A., Weiser G., Allison R.W. \& Campbell T. 2012. Veterinary Hematology and Clinical Chemistry. 2nd edn. Fort Collins: Willey-Blackwell, 762p.

20 Weidner N. \& Verbrugghe A. 2017. Current knowledge of vitamin D in dogs. Critical Reviews in Food Science and Nutrition. 57(18): 3850-3859. 